BMJ Open

Diabetes

Research

$\&$ Care

\title{
Effectiveness of diabetes self-
} management education and support via a smartphone application in insulintreated patients with type 2 diabetes: results of a randomized controlled trial (TRIGGER study)

\author{
Anne Meike Boels (D) , ${ }^{1}$ Rimke C Vos (D) , ${ }^{1,2}$ Lioe-Ting Dijkhorst-Oei, ${ }^{3,4}$ \\ Guy E H M Rutten ${ }^{1}$
}

To cite: Boels AM, Vos RC, Dijkhorst-0ei L-T, et al. Effectiveness of diabetes self-management education and support via a smartphone application in insulin-treated patients with type 2 diabetes: results of a randomized controlled trial (TRIGGER study). BMJ Open Diab Res Care 2019;7:e000981. doi:10.1136/ bmjdrc-2019-000981

- Additional material is published online only. To view please visit the journal online (http://dx.doi.org/10.1136/ bmjdrc-2019-000981).

This trial has been presented as a poster presentation during the EASD Conference in Berlin, October 2018.

Received 27 October 2019 Accepted 9 November 2019

Check for updates

C Author(s) (or their employer(s)) 2019. Re-use permitted under CC BY-NC. No commercial re-use. See rights and permissions. Published by BMJ.

For numbered affiliations see end of article.

Correspondence to Dr Anne Meike Boels; a.m.boels@umcutrecht.nl

\section{ABSTRACT}

Objective To investigate the effect of diabetes selfmanagement education and support via a smartphone app in individuals with type 2 diabetes on insulin therapy. Research design and methods Open two-arm multicenter parallel randomized controlled superiority trial. The intervention group $(n=115)$ received theory and evidence-based self-management education and support via a smartphone app (optionally two or six times per week, once daily at different times). The control group $(n=115)$ received care as usual. Primary outcome: HbA1c at 6 months. Other outcomes included $\mathrm{HbA} 1 \mathrm{c} \leq 53 \mathrm{mmol} /$ $\mathrm{mol}(\leq 7 \%)$ without any hypoglycemic event, body mass index, glycemic variability, dietary habits and quality of life. We performed multiple imputation and regression models adjusted for baseline value, age, sex, diabetes duration and insulin dose.

Results Sixty-six general practices and five hospital outpatient clinics recruited 230 participants. Baseline $\mathrm{HbA} 1 \mathrm{c}$ was comparable between groups $(8.1 \%$ and $8.3 \%$, respectively). At 6 months, the $\mathrm{HbA1c}$ was $63.8 \mathrm{mmol} /$ $\mathrm{mol}(8.0 \%)$ in the intervention vs $66.2 \mathrm{mmol} / \mathrm{mol}(8.2 \%)$ in the control group; adjusted difference $-0.93 \mathrm{mmol} / \mathrm{mol}$ $(-0.08 \%), 95 \% \mathrm{Cl}-4.02$ to $2.17 \mathrm{mmol} / \mathrm{mol}(-0.37 \%$ to $0.20 \%), p=0.557$. The odds for achieving an $\mathrm{HbA} 1 \mathrm{c}$ level $\leq 7 \%$ without any hypoglycemic event was lower in the intervention group: $\mathrm{OR} 0.87,95 \% \mathrm{Cl} 0.33$ to 2.35 . There was no effect on secondary outcomes. No adverse events were reported.

Conclusions This smartphone app providing diabetes self-management education and support had small and clinically not relevant effects. Apps should be more personalized and target individuals who think the app will be useful for them.

Trial registration number NTR5515.

\section{INTRODUCTION}

For individuals with type 2 diabetes mellitus, self-management is an essential part of their diabetes treatment, especially for those on insulin therapy. Diabetes self-management

\section{Significance of this study}

What is already known about this subject?

- Many studies on mHealth (healthcare delivered via mobile devices) have been conducted-only a few demonstrated beneficial effects

What are the new findings?

- The TRIGGER apps provides diabetes selfmanagement education, specifically developed for patients with type 2 diabetes mellitus on insulin therapy.

While there were no effects on primary and secondary outcomes, more than half of the users found that receiving the messages motivated them to live healthy.

How might these results change the focus of research or clinical practice?

- This study underlines the importance of patient involvement in the development of mHealth applications.

is difficult, and healthcare providers are only able to support and stimulate selfmanagement a few times a year.

A solution to provide ongoing diabetes self-management support could be the use of mobile health (mHealth): healthcare delivered via mobile devices. The effectiveness of mHealth as a vehicle for diabetes self-management education and support (DSME/S) has previously been investigated with a great variety of interventions: some trials provided general DSME $/ \mathrm{S},{ }^{1-4}$ others focused on specific topics such as medication adherence, ${ }^{56}$ physical activity, ${ }^{7}$ or insulin titration. ${ }^{8}$ While some found a statistically significant decrease in HbAlc of approximately 
$0.6 \%,{ }^{23}$ others did not. ${ }^{178}$ Only a few studies analyzed the prespecified sample size ${ }^{127}$; many studies were underpowered or were pilot studies with small sample size..$^{3-58}$ All but two of these trials ${ }^{58}$ included mostly patients who were not on insulin therapy. Patients on insulin therapy might have differential self-management needs and hence might benefit more from mHealth interventions that are specifically developed for them. Therefore, the aim of this study was to investigate the effect of DSME/S via a smartphone app in individuals with type 2 diabetes on insulin therapy.

\section{MATERIALS AND METHODS}

\section{Study design}

We conducted an open two-arm multicenter randomized controlled superiority trial with parallel groups and equal randomization (1:1): 'the TRIGGER study'. For more details, see the study design article. ${ }^{9}$

\section{Study population and setting}

Participants were recruited between December 2015 and December 2017 in general practices and hospital outpatient clinics across the Netherlands. Individuals with type 2 diabetes were eligible when they were sufficiently fluent in Dutch, used insulin since $\geq 3$ months, had an HbAlc $>53 \mathrm{mmol} / \mathrm{mol}(>7 \%)$, were aged $40-70$ years, and were treated for their diabetes by the recruiting healthcare provider. Patients were excluded when they had a history of alcoholism, drug abuse, dementia or a major psychiatric disorder. All eligible individuals received an information letter and were recruited by their diabetes care provider. When they agreed to participate, written informed consent was obtained. In primary care, the reasons for not participating, as well as age and sex of those who declined to participate, were recorded.

\section{Intervention}

A smartphone app provided participants with DSME/S delivered as text messages on the following topics: dietary habits, physical activity, prevention of hypoglycemia, and glucose control (including glycemic variability). The text messages were unidirectional and contained specific goals, healthy lifestyle information and challenges, or questions (online supplementary appendix 1). Content was based on (inter) national guidelines and on previous mHealth studies. The text messages were critically reviewed by a dietician, physiotherapist, practice nurse and by two individuals with type 2 diabetes on insulin therapy. Messages were framed grammatically correct, free of 'SMS language', benefit oriented, polite, non-aggressive and directive. ${ }^{10} 11$ They were in Dutch only. The theory behind the intervention was based on 'behavioural triggers', which play an important role in behavior change. ${ }^{12-15} \mathrm{~A}$ trigger stimulates the individual to engage in health-promoting behavior and can be the last factor to overcome barriers.

The smartphone app was compatible with iOS and Android operating systems. Users received a push notification when a new text message was available. When users did not open the app during the first 24 hours after a message had been sent, they received a short message service (SMS) reminder. The number of reminder SMS was monitored, as a measurement of compliance. The timing of the messages was either random between 09:30 and 20:00 or at times associated with the content of the message (eg, a text message on dietary habits correlated with traditional mealtimes).

The intervention was tailored, according to patient's preferences:

- The topics: three or four out of four topics. Hypoglycemia was a mandatory topic, complemented by dietary habits, physical activity, or glucose control.

- The frequency: two or six times per week, one text message per day.

- The option to prolong the intervention with another 3 months after the first 6 months. During this period the patients received text messages with unaltered frequency and topics.

Apart from receiving app triggers, the intervention group received care as usual for their type 2 diabetes according to the national diabetes guidelines. ${ }^{16}$

\section{Control group}

Patients randomized to the control group received only care as usual, but were offered the opportunity to use the smartphone app after their follow-up had been completed.

\section{Outcomes}

The primary outcome was the HbAlc level after 6 months in the smartphone app group compared with the control group. As a coprimary outcome we analyzed the proportion of patients who achieved an HbAlc level $\leq 53 \mathrm{mmol} /$ mol $(\leq 7 \%)$ without any hypoglycemic event. Secondary outcomes measured at 6 months were:

- Body mass index (BMI), blood pressure, lipid profile.

- Presence of hypoglycemic events.

- Glycemic variability (since evidence suggests this could be an independent risk factor for diabetesrelated complications). ${ }^{17}$

- Self-care behavior (summary of diabetes self-care activities).$^{18}$

- Dietary habits (Kristal's food frequency questionnaire).$^{19}$

- Physical activity (International Physical Activity Questionnaires). ${ }^{20}$

- Health status (EQ-5D-5L questionnaire and visual analog scale, Short Form-36 Health Survey). ${ }^{21} 22$

- Diabetes-dependent quality of life (Audit of DiabetesDependent Quality of Life). ${ }^{23}$

- Diabetes treatment satisfaction (Diabetes Treatment Satisfaction Questionnaire).$^{24}$

- Satisfaction and usability of the app (only intervention group, self-designed questionnaire).

Online supplementary appendix 2 describes all questionnaires. 
Moreover, after 9 months we assessed in the intervention group only: $\mathrm{HbAlc}$, proportion of patients who achieved an $\mathrm{HbAlc} \leq 7 \%$ without any hypoglycemic event, BMI and EQ-5D profile.

\section{Data collection}

Data were collected via online questionnaires, paper patient diaries, and online case report forms. Follow-up measurements overlapped with regular diabetes monitoring visits, usually at three monthly intervals.

At baseline and after 6 months of follow-up, patients completed the online questionnaires; the intervention group also completed one questionnaire after 9 months.

Patients kept a diary in which they recorded any hypoglycemic events during the study. Moreover, once weekly they recorded their fasting plasma glucose, two preprandial values, and bedtime glucose level. Unfortunately, during the study the compliance to the diary proved to be very low. We therefore also evaluated hypoglycemic events by sending participants who did not send back the diary a short questionnaire. If this questionnaire too was not returned, we scrutinized their electronic medical records on any recorded hypoglycemic event.

Practice and diabetes nurses recorded all clinical variables on an online case report form completed at baseline, after 6 months, and for the intervention group also after 9 months of follow-up. BMI and blood pressure were measured according to the standard protocol of the site; HbAlc and lipid profile were assessed by local laboratories.

\section{Sample size}

Based on the decrease in HbAlc in previous mHealth studies, we expected a mean difference in HbAlc level of $0.41 \%$ with an SD of $1.1 \%$ between groups after 6 months. ${ }^{25} 26$ To detect this difference with an $80 \%$ power and an $\alpha$ of $5 \%$ after 6 months, 228 patients with type 2 diabetes (114 per treatment group) were needed. We used SAS V.9.4 (SAS) for the sample size calculation.

\section{Randomization, allocation concealment, blinding}

Patients were individually randomized using simple, fixed block randomization. Randomization was performed centrally at the research center using a web-based computerized random number generator provided by an independent contractor, in the order in which participants were enrolled by their healthcare provider. The randomization allocation was forwarded to the patients approximately 10 days after written informed consent, enabling patients to complete the baseline questionnaires before they knew to which arm they were randomized. Patients were not blinded due to the nature of the intervention.

\section{Changes of methods after trial commencement}

Initially, this study was to be conducted in primary care only. Since recruitment was slower than anticipated, we also recruited patients from hospital outpatient clinics. In the Netherlands, $85 \%$ of individuals with type 2 diabetes are treated in primary care; when problems such as persisting inadequate glycemic control occur, patients are referred to hospital outpatient clinics.

As mentioned above, the compliance to the paper patient diary was low. Besides, while we prespecified a hypoglycemic event as plasma glucose $<63 \mathrm{mg} / \mathrm{dL}$ $(<3.5 \mathrm{mmol} / \mathrm{L})$, participants reported hypoglycemic events with higher glucose levels. The alternative approaches to assess hypoglycemic episodes-questionnaire and electronic medical record-did not take plasma glucose level into account; hence we decided to accept any self-reported hypoglycemic event irrespective of the plasma glucose level. Since the recall of hypoglycemic events is likely to be more biased compared with keeping a diary, we only evaluated whether or not participants experienced any hypoglycemic event during follow-up, instead of the number of hypoglycemic episodes. Lastly, since waist circumference was missing in more than half of the participants at follow-up, we did not analyze this outcome.

We did not prespecify any sensitivity analyses, but we did perform two (see the Analysis section).

\section{Analysis}

We compared age and sex of the study population to those who declined to participate to assess possible selection. Since the exclusion of participants with missing data can lead to bias, we used multiple imputation to deal with missing data. Characteristics of participants with any missing value for the primary outcome analysis, and those with complete data are shown in online supplementary appendix 3, suggesting data are missing at random. We created 10 imputed data sets with 30 iterations under the 'missing at random' assumption.

Participants were analyzed according to the intentionto-treat principle. Continuous outcomes were analyzed with general linear models, binary outcomes with logistic regression. For each outcome, we performed an unadjusted univariable analysis, and a multivariable analysis corrected for age, sex, duration of diabetes, baseline insulin dose, and baseline value of the outcome.

To assess glycemic variability we calculated the coefficient of variation $(\mathrm{CoV})$ : the SD divided by the mean * $100 .^{17}$

Because of the large proportion of missing diaries, we did not perform multiple imputation for this outcome and we only present the results of glycemic variability graphically. We performed two sensitivity analyses: (1) in primary care participants, since we designed the app specifically for this population; (2) in those who found that the messages were applicable to them (ie, those who scored $>3$ on item 'the messages were applicable to me', scale range: $0-5$ ).

We analyzed the difference between HbAlc, BMI and EQ-5D profile at 9 and 6 months in those who continued using the app compared with those who did not continue with a general linear model corrected for age, sex, duration of diabetes, baseline insulin dose and baseline value. 


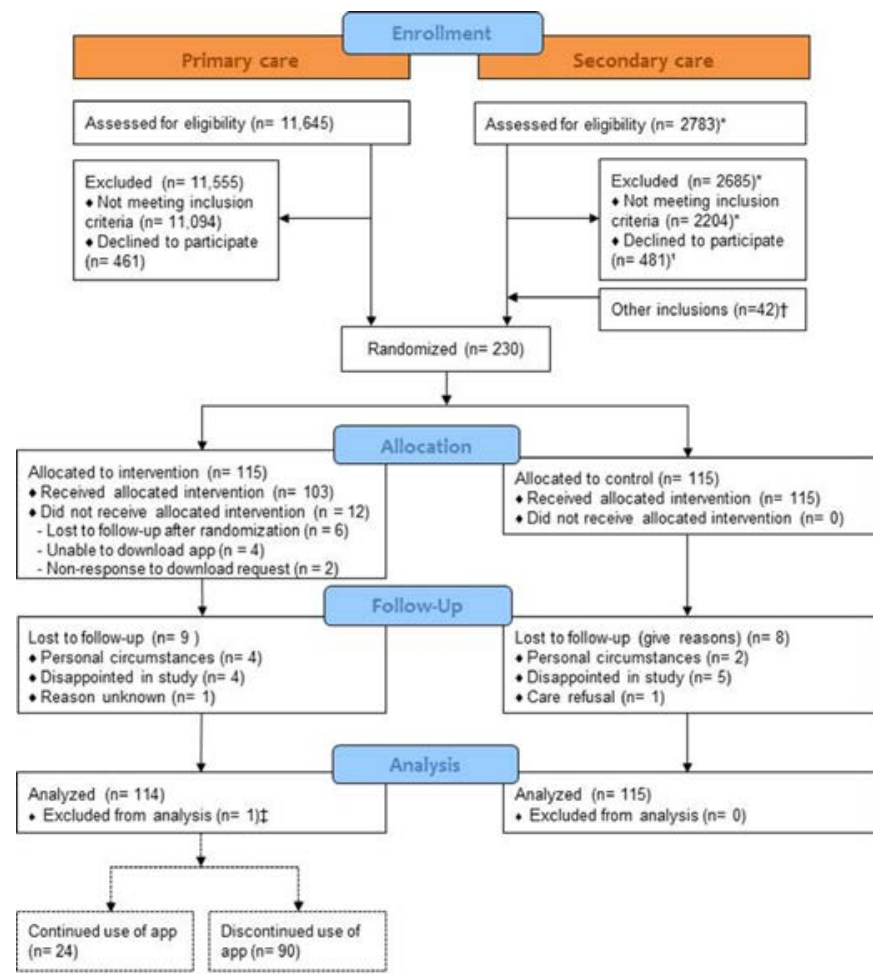

Figure 1 Flow diagram of participants.

${ }^{*}$ Complete screening information only available from two hospitals

†Because of incomplete screening information, only the inclusions from three hospitals are shown

$\ddagger$ One participant was excluded from analysis because too little information was available for multiple imputation

Answers on the satisfaction and usability of the app questionnaire (continuous scale range: $0-5$ ) were categorized into disagree $(<2)$, neutral $(2-3)$ and agree $(>3)$ and were analyzed only for those who completed the questionnaire.

We used RStudio V.1.0.143 for the statistical analyses and mice 3.3.0 package for multiple imputation.

\section{RESULTS}

Participation, missing data and study population

Sixty-six general practices and five hospital outpatient clinics recruited 230 participants; of the 66 general practices, 26 were unable to recruit any participant. In primary care, 90 of the 551 individuals who fulfilled the inclusion criteria participated $(16.3 \%$, figure 1$)$. In secondary care, 140 participants were included (participation rates per hospital ranging from $9.9 \%$ to $17.0 \%$ ).

Information on patients who declined to participate was available of 368 individuals from 48 general practices; the mean age of those who declined to participate was $60.8 \pm 8.2$ years and $40.2 \%$ were women, which is comparable to those who did participate $(59.1 \pm 7.5$ years, $39.1 \%$ women). The main reasons for not participating were 'not interested' $(38.5 \%)$ or 'not owning a smartphone' $(30.3 \%)$. During follow-up, 17 participants were lost to
Table 1 Baseline characteristics of the study population $(n=230)$

\begin{tabular}{|c|c|c|}
\hline \multirow{2}{*}{$\begin{array}{l}\text { Characteristic, mean (SD) or } \\
\text { number }(\%)\end{array}$} & \multirow{2}{*}{$\begin{array}{l}\text { Intervention } \\
\mathrm{n}=115\end{array}$} & \multirow{2}{*}{$\begin{array}{l}\text { Control } \\
n=115\end{array}$} \\
\hline & & \\
\hline Age (years) & $58.6(8.2)$ & $59.7(6.8)$ \\
\hline Sex: female & $48(41.7)$ & $43(37.4)$ \\
\hline Educational level & * & \\
\hline High & $38(33.3)$ & $44(38.3)$ \\
\hline Middle & $65(57.0)$ & $62(53.9)$ \\
\hline Low & $11(9.6)$ & $9(7.8)$ \\
\hline Ethnicity: Caucasian & $92(80.7)^{*}$ & $96(83.5)$ \\
\hline Smoking & * & \\
\hline Yes & $20(17.5)$ & $21(18.3)$ \\
\hline Former & $42(36.8)$ & $45(39.1)$ \\
\hline Never & $52(45.6)$ & $49(42.6)$ \\
\hline Diabetes duration (years) & $14.9(8.3)^{*}$ & $14.3(7.7)$ \\
\hline Treatment in secondary care & $73(63.5)$ & $67(58.3)$ \\
\hline Microvascular complications & $65(57.0)^{*}$ & $66(57.4)$ \\
\hline Macrovascular complications & $23(20.2)^{*}$ & $33(28.7)$ \\
\hline Injection frequency & * & \\
\hline Once daily & $37(32.5)$ & $36(31.3)$ \\
\hline Twice daily & $6(5.3)$ & $10(8.7)$ \\
\hline Four times daily & 63 (55.3) & $55(47.8)$ \\
\hline Other & $8(7.0)$ & $14(12.2)$ \\
\hline Metformin & $92(80.7)^{\star}$ & $91(79.1)$ \\
\hline SU derivatives & $22(19.3)^{\star}$ & $28(24.3)$ \\
\hline GLP-1 receptor agonist & $15(13.2)^{*}$ & $8(7.0)$ \\
\hline DPP-4 inhibitors & $2(1.8)^{\star}$ & $3(2.6)$ \\
\hline SGLT2 inhibitors & $7(6.1)^{*}$ & $5(4.3)$ \\
\hline
\end{tabular}

${ }^{*} \mathrm{n}=114$.

DPP-4, dipeptidyl peptidase-4; GLP-1, glucagon-like peptide-1; SGLT2, sodium-glucose cotransporter 2; SU, sulfonylurea.

follow-up (figure 1). For our primary outcome analysis, $4.7 \%$ of the values were missing, distributed among 49 participants $(21.3 \%)$ (online supplementary appendix $3)$. For one participant we were unable to impute missing data.

Mean age was $58.6 \pm 8.2$ years in the intervention group versus $59.7 \pm 6.8$ in the control group, $41.7 \%$ and $37.4 \%$ were women, respectively. Tables 1 and 2 show more baseline characteristics of our study population. Both groups were well matched.

\section{App preferences}

Most patients chose to receive two messages weekly; only 38 participants $(33 \%)$ chose to receive six messages weekly. Almost half of the participants chose all four categories of messages, while 64 participants $(55.7 \%)$ chose three categories. Dietary habits were most often chosen $(86.1 \%)$, followed by glucose control $(83.5 \%)$; least often chosen was physical activity $(74.8 \%)$. 


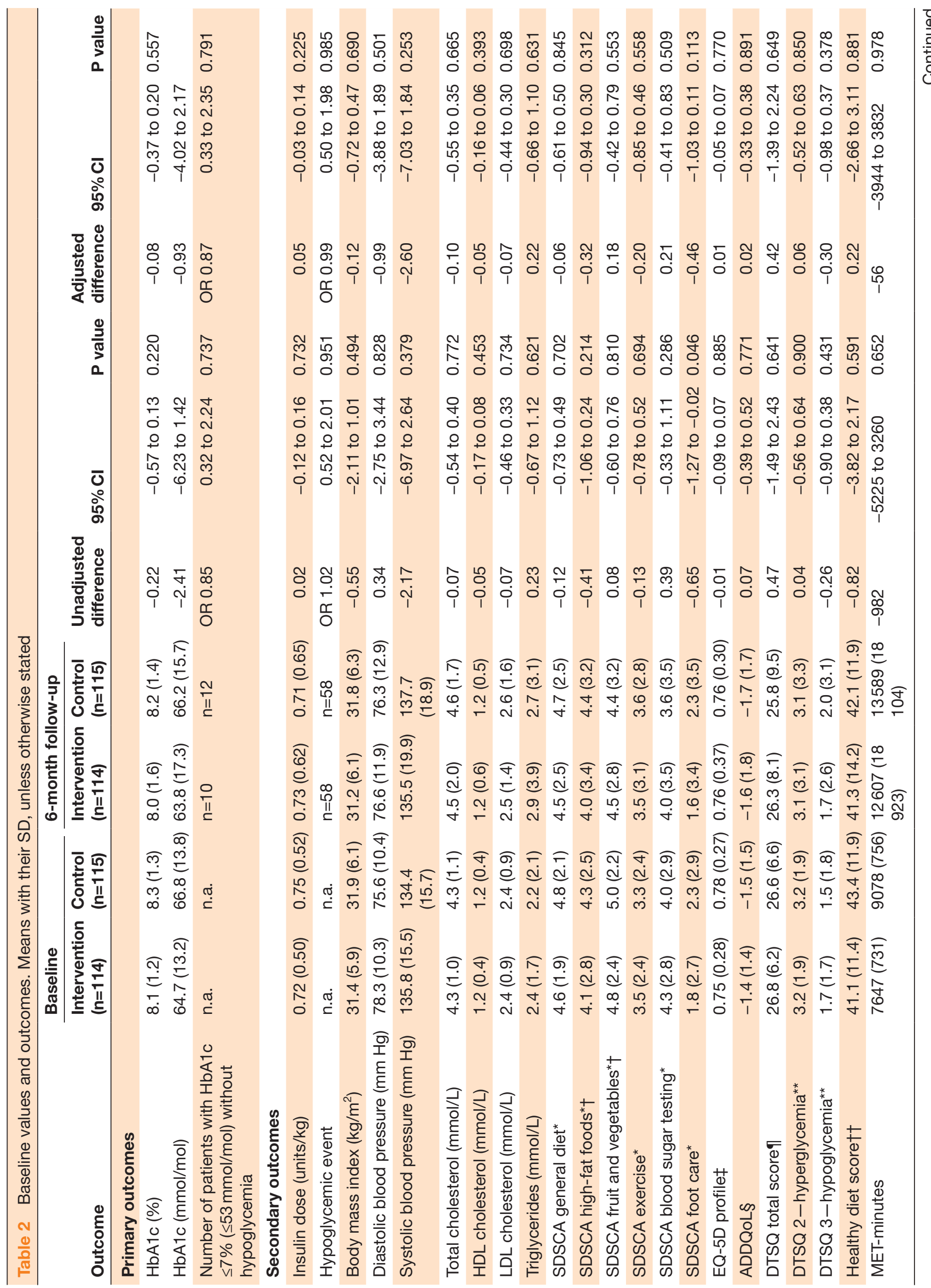




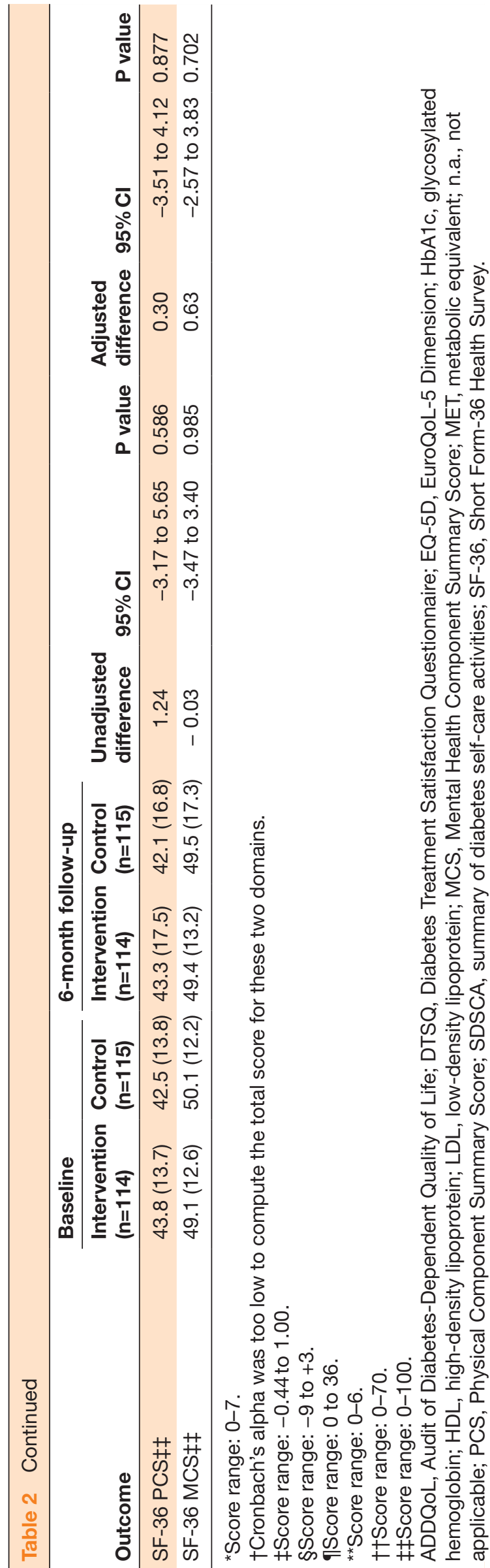

Primary outcomes

At follow-up, the HbA1c level was slightly lower in the intervention group in both the unadjusted and the adjusted analysis, but this difference was not statistically significant (table 2). The odds for achieving an HbAlc level $\leq 53 \mathrm{mmol} / \mathrm{mol}(\leq 7 \%)$ without any hypoglycemic event was marginally lower in the intervention group, but this difference was also not statistically significant (table 2). The sensitivity analyses among primary care participants resulted in a larger adjusted mean HbAlc difference of $-2.21 \mathrm{mmol} / \mathrm{mol}(-0.20 \%), \mathrm{p}=0.403$ (online supplementary appendix 4 ). When restricting the analysis to those who found messages applicable to them, the adjusted mean $\mathrm{HbA1c}$ difference was $-2.40 \mathrm{mmol} / \mathrm{mol}$ $(-0.22 \%), \mathrm{p}=0.231$ (online supplementary appendix 4$)$.

\section{Secondary outcomes}

At follow-up, there were no statistically significant differences between the intervention and control group in any of the secondary outcomes (table 2). Figure 2 shows the glycemic variability over 6 months, expressed as $\mathrm{CoV}$ of those who completed the diary.

\section{Safety, compliance, technical issues and satisfaction with the} app

No adverse events were reported. During the trial, all but one participant received at least one reminder SMS. The median number of reminder SMS sent was 20 (range 1-123). We received 26 notifications regarding technical issues such as being unable to find the app, not able to download the app, unable to register the app or accidently having deleted the app. Of 115 participants randomized to the control group, 13 registered the app after the trial had finished. Table 3 shows the results of the applicability and usability of the app: $61.0 \%$ found that receiving the messages motivated them to live healthy; $44.4 \%$ found the messages applicable to them.

\section{Cost-effectiveness}

We did not perform the prespecified cost-effectiveness analysis, ${ }^{9}$ since it seemed to be redundant based on the absence of any effects, and on similar healthcare resource usage between the groups.

\section{Prolonged follow-up}

Of the 115 participants randomized to the intervention group, 24 prolonged the intervention with another 3 months. In those who continued using the app, the HbAlc after 9 months was $0.52 \mathrm{mmol} / \mathrm{mol}(0.05 \%)$ lower compared with the level at 6 months. In those who did not continue using the app, the HbAlc after 9 months remained equal to the level at 6 months. The odds for achieving an HbAlc level $\leq 53 \mathrm{mmol} / \mathrm{mol}(\leq 7 \%)$ without any hypoglycemic event did not alter in the period between 6 and 9 months, nor were there differences in BMI and EQ-5D profile (data not shown). 


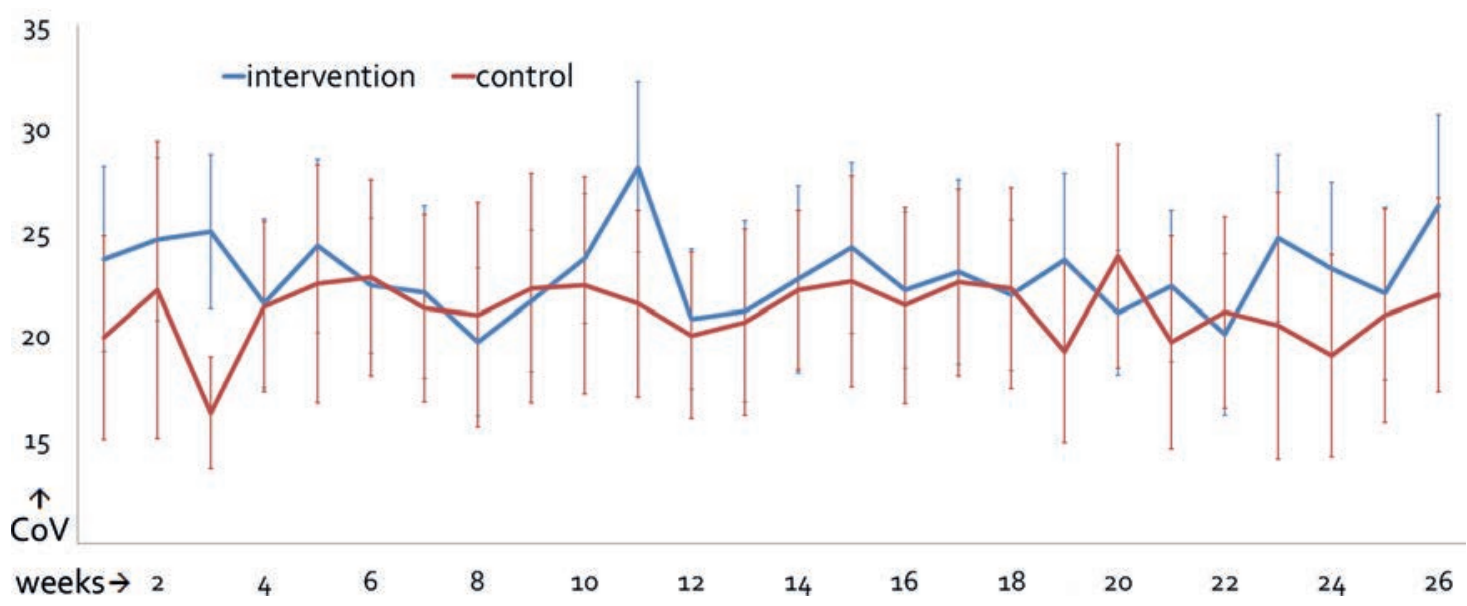

Figure 2 Glycemic variability expressed as coefficient of variation (CoV, percentage) with $95 \% \mathrm{Cl}$ ( $\mathrm{n}$ minimum=45 (week 1 ); $\mathrm{n}$ maximum=69 (week 15)).

\section{DISCUSSION}

\section{Summary of main findings}

This trial investigated the effect of DSME/S via a smartphone app in individuals with type 2 diabetes on insulin therapy. The effects were absent or marginal and not clinically relevant. Participants rated the applicability and usability of the app quite diverse: approximately as many participants found that receiving the messages motivated them to live healthy, as found the opposite. More than half of participants did not find the messages applicable to them, and often forgot to make use of them.

\section{Interpretation}

The overall participation rate in this mHealth trial was $9.9 \%-17.0 \%$. A qualitative study found that patients with diabetes (compared with chronic obstructive pulmonary disease and cardiovascular diseases) were most willing to use eHealth. ${ }^{27}$ Nevertheless, like other mHealth trials we experienced problems with recruiting participants. ${ }^{28} 29 \mathrm{In}$ 2016 almost $90 \%$ of the Dutch population aged 45-65 years had access to a mobile phone with internet capacity, but for those above 65 years this was only $50 \% .^{30}$ Approximately one-third of those who were asked to participate in our trial said they did not own a smartphone. We probably overestimated the proportion of patients with a smartphone. Moreover, since self-management interventions are not 'one-size-fits-all', ${ }^{31}$ many of those who were asked to participate simply could not have wanted to use mHealth. This 'one-size-does-not-fit-all' concept is supported by the fact that two-thirds of our participants chose the least intensive frequency, and more than half of the participants chose three instead of four topics.

The sensitivity analysis among those who found messages applicable to them suggests that the intervention might be more effective in this group. While this is something one might expect, it shows that-with an overall lack of effectiveness-for subgroups this app could be useful, surely when we take into account that self-management interventions should be personalized. ${ }^{31}$ We chose to perform one sensitivity analysis among those who found the messages applicable. We could have performed 12

Table 3 Satisfaction with and applicability of the app (disagree: <2; neutral: 2-3; agree: >3; on a continuous scale, range 0-5)

\begin{tabular}{lllll}
\hline & $\mathbf{n}$ & \multicolumn{1}{c}{$\begin{array}{l}\text { Disagree } \\
\text { (\%) }\end{array}$} & $\begin{array}{l}\text { Neutral } \\
\text { (\%) }\end{array}$ & $\begin{array}{l}\text { Agree } \\
\text { (\%) }\end{array}$ \\
\hline Receiving the messages motivated me to live healthy. & 82 & 19.5 & 19.5 & 61.0 \\
\hline Receiving the messages taught me a lot about diabetes. & 81 & 21.0 & 27.2 & 51.9 \\
\hline The messages were sent at the right moments. & 81 & 13.6 & 25.9 & 60.5 \\
\hline The information in the messages was difficult to understand. & 81 & 71.6 & 4.9 & 23.5 \\
\hline If I were to proceed with the program I would want to receive fewer messages. & 81 & 38.3 & 14.8 & 46.9 \\
\hline I would recommend this application to family and friends with diabetes. & 81 & 25.9 & 13.6 & 60.5 \\
\hline The messages prompted me to improve the healthiness of my diet. & 80 & 42.5 & 20.0 & 37.5 \\
\hline The messages encouraged me to exercise more. & 81 & 43.2 & 19.8 & 37.0 \\
\hline Because of the messages, I am more capable of dealing with hypoglycemia. & 80 & 47.5 & 16.3 & 36.3 \\
\hline The messages were applicable to me. & 81 & 28.4 & 27.2 & 44.4 \\
\hline I often made use of the messages (eg, I took the stairs or cooked a healthy meal) & 81 & 33.3 & 23.5 & 43.2 \\
\hline I often forgot to make use of the messages & 81 & 35.8 & 13.6 & 50.6 \\
\hline
\end{tabular}


sensitivity analyses for each question, thereby identifying a subgroup of participants for whom the app works best. This (data-driven analysis) was however beyond the scope of this research.

While we involved patients with type 2 diabetes in critically reviewing the content of the messages, we did not involve patients in earlier stages of the design of the intervention and the trial. We therefore could have misinterpreted the participants' needs, which is supported by the fact that most participants did not find the messages applicable to them. We made an attempt to personalize the messages by enabling participants to choose the frequency and topics, but the low proportion of participants who found the messages applicable shows that this was not personalized enough. We initially designed the intervention for patients with type 2 diabetes treated in primary care, but ended up with the majority of participants recruited from outpatient clinics of hospitals. The sensitivity analysis suggested that the effect of the intervention on the HbAlc level was larger in the primary care participants. In the Netherlands, patients treated at hospital outpatient clinics have previously been treated in primary care. For these patients, who have received diabetes education from the practice nurse, general practitioner, diabetes nurse and endocrinologist, additional basic DSME/S via an app likely does not add anything new to their knowledge, abilities and skills. The theory behind the intervention was based on 'behavioural triggers'. While a trigger can prompt individuals to engage in health-promoting behavior, individuals need to have a certain level of ability and motivation for the trigger to work. ${ }^{12}$

\section{Comparison with literature}

A trial conducted in Bangladesh investigated a similar intervention: DSME sent via SMS for 6 months. ${ }^{2}$ In this trial the intervention effectively lowered the HbAlc level in the intervention group. The patients included in this trial, however, could hardly be more different from our population: their median diabetes duration was 1 year and none of them used insulin. Evidently, the trial was conducted in a lower middle-income country and moreover their population only had received 9 years of education (unpublished data). Our study population was relatively highly educated compared with the general Dutch type 2 diabetes population. ${ }^{32}$ These highly educated patients could also benefit less from DSME/S.

\section{Study strengths and limitations}

While age and sex of those who declined to participate were similar to those who participated, our participants were different compared with a previous European population on insulin therapy. ${ }^{33}$ Our population was younger, but with a longer diabetes duration and more microvascular complications. Moreover, our study population had a higher HbAlc level and was less satisfied with the diabetes treatment. ${ }^{33}$ These differences can be explained by our inclusion criteria, which may have resulted in a study population that had been using insulin for many years, but still fails to reach good glycemic control and is less satisfied with the treatment. Hence, our results may not be fully generalizable to all people with type 2 diabetes who use insulin. Another limitation is that we did not monitor the use of other diabetes apps. Participants randomized to the control arm could have downloaded another diabetes app, which could have biased our results towards null. As mentioned earlier, the app was intended for individuals treated in primary care; moreover we hypothesized that the app would be especially suited for individuals with a low socioeconomic status. ${ }^{9}$ Nevertheless, we included mainly secondary care patients, and those with a high educational level.

Strengths of this trial are the large sample size and the statistical analysis in which we corrected for prognostic determinants. Moreover, we only included people with type 2 diabetes, while other trials have included both type 1 and type 2 diabetes ${ }^{534}$; one trial found an overall beneficial effect of mHealth, but in the subgroup restricted to type 2 diabetes no statistically significant effects were found. ${ }^{34}$

\section{Implications}

This study shows that our theory and evidence-based mHealth intervention was not effective, probably because it was not designed 'bottom up' and not enough personalized. To be effective, apps should optimally incorporate the needs of end-users. While in our trial participants could choose the frequency of and topics of the intervention, future interventions should target specific populations taking into account their needs and expectations.

\section{Author affiliations}

1Julius Center for Health Sciences and Primary Care, University Medical Center Utrecht, Utrecht, The Netherlands

${ }^{2}$ LUMC-Campus The Hague, Leiden University Medical Center, Hague, The Netherlands

${ }^{3}$ Department of Internal Medicine, Meander Medisch Centrum, Amersfoort, Utrecht, The Netherlands

${ }^{4}$ Department of Internal Medicine, Amsterdam UMC-Locatie VUMC, Amsterdam, Noord-Holland, The Netherlands

Acknowledgements The authors thank the physicians and nurses, and the people with type 2 diabetes from general practices and outpatient hospital clinics for participating in the study. The authors also thank Maria Schipper (Julius Center for Health Sciences and Primary Care, Department of Biostatistics and Research Support, University Medical Center Utrecht, The Netherlands) for her statistical support, and Ivonne Sluijs (Julius Center for Health Sciences and Primary Care, Department of Cardiovascular Epidemiology, University Medical Center Utrecht, The Netherlands) for her advice regarding the food frequency questionnaire. We acknowledge the help of Ron van Leeuwen, Paul van den Bogaert, Adrienne Weinberg, Sijda Groen, Nicolien van der Hart and Martine Dogger for reviewing the content of the app messages. We thank Curavista for programming the software for the smartphone app for this study.

Contributors GEHMR and RCV designed the study. AMB developed the smartphone app content and participated in the design of the study. AMB coordinated the fieldwork, analyzed the data and drafted the manuscript. LTDO coordinated the fieldwork in one site. GEHMR, RCV and LTDO reviewed and edited the manuscript. All authors read and approved the final manuscript. AMB is the guarantor of this work and, as such, had full access to all the data in the study and takes responsibility for the integrity of the data and the accuracy of the data analysis. 
Funding The study was funded by Sanofi-Aventis.

Disclaimer No names of insulin, neither specialties nor generic ones, have been mentioned in any app message or in other information to the patient. SanofiAventis had no role in the design of the study; in the data collection, analysis, and interpretation of data; in the writing of the manuscript; and in the decision to submit the manuscript for publication.

Competing interests GEHMR received fees from Novo Nordisk for consultancy and lecturing.

\section{Patient consent for publication Not required.}

Ethics approval The Medical Ethical Committee of the University Medical Center Utrecht approved the study protocol and the trial was prospectively registered in the Dutch trial register.

Provenance and peer review Not commissioned; externally peer reviewed.

Data availability statement Data are available upon reasonable request.

Open access This is an open access article distributed in accordance with the Creative Commons Attribution Non Commercial (CC BY-NC 4.0) license, which permits others to distribute, remix, adapt, build upon this work non-commercially, and license their derivative works on different terms, provided the original work is properly cited, appropriate credit is given, any changes made indicated, and the use is non-commercial. See: http://creativecommons.org/licenses/by-nc/4.0/.

ORCID iDs

Anne Meike Boels http://orcid.org/0000-0003-0807-1287

Rimke C Vos http://orcid.org/0000-0003-1074-6255

\section{REFERENCES}

1 Arora S, Peters AL, Burner E, et al. Trial to Examine Text MessageBased mHealth in Emergency Department Patients With Diabetes (TExT-MED): A Randomized Controlled Trial. Ann Emerg Med 2014:63:745-54.

2 Shariful Islam SM, Niessen LW, Ferrari U, et al. Effects of mobile phone SMS to improve glycemic control among patients with type 2 diabetes in Bangladesh: a prospective, parallel-group, randomized controlled trial. Diabetes Care 2015;38:e112-3.

3 Williams ED, Bird D, Forbes AW, et al. Randomised controlled trial of an automated, interactive telephone intervention (TLC diabetes) to improve type 2 diabetes management: baseline findings and sixmonth outcomes. BMC Public Health 2012;12:602.

4 Faridi Z, Liberti L, Shuval K, et al. Evaluating the impact of mobile telephone technology on type 2 diabetic patients' self-management: the NICHE pilot study. J Eval Clin Pract 2008;14:465-9.

5 Gatwood J, Balkrishnan R, Erickson SR, et al. The impact of tailored text messages on health beliefs and medication adherence in adults with diabetes: a randomized pilot study. Res Social Adm Pharm 2016;12:130-40.

6 Vervloet M, van Dijk L, de Bakker DH, et al. Short- and long-term effects of real-time medication monitoring with short message service (SMS) reminders for missed doses on the refill adherence of people with Type 2 diabetes: evidence from a randomized controlled trial. Diabet Med 2014;31:821-8.

7 Agboola S, Jethwani K, Lopez L, et al. Text to move: a randomized controlled trial of a text-messaging program to improve physical activity behaviors in patients with type 2 diabetes mellitus. J Med Internet Res 2016;18:e307.

8 Bee YM, Batcagan-Abueg APM, Chei C-L, et al. A smartphone application to deliver a treat-to-target insulin titration algorithm in insulin-naive patients with type 2 diabetes: a pilot randomized controlled trial. Diabetes Care 2016;39:e174-6.

9 Boels AM, Rutten G, Zuithoff N, et al. Effectiveness of diabetes self-management education via a smartphone application in insulin treated type 2 diabetes patients - design of a randomised controlled trial ('TRIGGER study'). BMC Endocr Disord 2018;18:74.

10 Akl EA, Oxman AD, Herrin J, et al. Framing of health information messages. Cochrane Database Syst Rev 2011;22.

11 Muench F, van Stolk-Cooke K, Morgenstern J, et al. Understanding messaging preferences to inform development of mobile goaldirected behavioral interventions. J Med Internet Res 2014;16:e14
12 Fogg B. A behavior model for persuasive design. Proceedings of the 4th International Conference on Persuasive Technology, 2009.

13 Janz NK, Becker MH. The health belief model: a decade later. Health Educ Q 1984:11:1-47.

14 Leventhal H, Leventhal EA, Contrada RJ. Self-Regulation, health, and behavior: a perceptual-cognitive approach. Psychol Health 1998:13:717-33.

15 Prochaska JO, Redding CA, Evers KE. The transtheoretical model and stages of change. In: Health behaviour and health education: theory, research, and practice, 2002: 99-120.

16 Rutten G, De Grauw WJC, Nijpels G, et al. NHG-Standaard diabetes mellitus type 2 (derde herziening). Huisarts Wet 2013;56:512-25.

17 Ceriello A, Monnier L, Owens D. Glycaemic variability in diabetes: clinical and therapeutic implications. The Lancet Diabetes \& Endocrinology 2018;8587.

18 Toobert DJ, Hampson SE, Glasgow RE. The summary of diabetes self-care activities measure: results from 7 studies and a revised scale. Diabetes Care 2000;23:943-50.

19 Kristal AR, Shattuck AL, Henry HJ. Patterns of dietary behavior associated with selecting diets low in fat: reliability and validity of a behavioral approach to dietary assessment. J Am Diet Assoc 1990;90:214-20.

20 Vandelanotte C, De Bourdeaudhuij I, Philippaerts R, et al. Reliability and validity of a computerized and Dutch version of the International physical activity questionnaire (IPAQ). Journal of Physical Activity Health 2005;2:63-75.

21 The Euroqol Group. EuroQol - a new facility for the measurement of health-related quality of life. Health Policy 1990;16:199-208.

22 Aaronson NK, Muller M, Cohen PDA, et al. Translation, validation, and Norming of the Dutch language version of the SF-36 health survey in community and chronic disease populations. J Clin Epidemiol 1998;51:1055-68.

23 Bradley C, Todd C, Gorton T, et al. The development of an individualized questionnaire measure of perceived impact of diabetes on quality of life: the ADDQoL. Qual Life Res 1999;8:79-91.

24 Bradley C. Diabetes treatment satisfaction questionnaire. In: Handbook of psychology and diabetes, 1994: 111-32.

25 Arambepola C, Ricci-Cabello I, Manikavasagam P, et al. The impact of automated brief messages promoting lifestyle changes delivered via mobile devices to people with type 2 diabetes: a systematic literature review and meta-analysis of controlled trials. $J$ Med Internet Res 2016;18:e86.

26 Cui M, Wu X, Mao J, et al. T2Dm self-management via smartphone applications: a systematic review and meta-analysis. PLoS One 2016;11:e0166718

27 Huygens MWJ, Vermeulen J, Swinkels ICS, et al. Expectations and needs of patients with a chronic disease toward self-management and eHealth for self-management purposes. BMC Health Serv Res 2016;16:1-11.

28 Capozza K, Woolsey S, Georgsson M, et al. Going mobile with diabetes support: a randomized study of a text Message-Based personalized behavioral intervention for type 2 diabetes self-care. Diabetes Spectrum 2015;28:83-91.

29 Thies K, Anderson D, Cramer B. Lack of adoption of a mobile APP to support patient self-management of diabetes and hypertension in a federally qualified health center: interview analysis of staff and patients in a failed randomized trial. JMIR Human Factors 2017;4:e24

30 CBS StatLine. Internet; toegang, gebruik en faciliteiten, 2016

31 Trappenburg J, Jonkman N, Jaarsma T, et al. Self-Management: one size does not fit all. Patient Educ Couns 2013;92:134-7.

32 Rutten GEHM, van Vugt HA, de Weerdt I, et al. Implementation of a structured diabetes consultation model to facilitate a PersonCentered approach: results from a nationwide Dutch study. Diabetes Care 2018;41:688-95.

33 Boels AM, Vos RC, Hermans TGT, et al. What determines treatment satisfaction of patients with type 2 diabetes on insulin therapy? an observational study in eight European countries. BMJ Open 2017:7:e016180.

34 Dobson R, Whittaker R, Jiang Y, et al. Effectiveness of text message based, diabetes self management support programme (SMS4BG): two arm, parallel randomised controlled trial. BMJ 2018;361. 